\title{
Fuentes para el estudio de la religion popular española
}

\author{
Marti GeLABERTó Vilagran \\ Centre de Recherches Historiques \\ Ecole des Hautes Etudes en Sciences Sociales (EHESS). Paris
}

\begin{abstract}
RESUMEN
El articulo propone una aproximación al análisis de algunas de las principales fuentes para el estudio de la religiosidad popular en España durante el Antiguo Régimen. Dichas fuentes son las utilizadas frecuentemente por los historiadores de las mentalidades: sermonarios y catecismos, sínodos diocesanos, visitas pastorales, libros litúrgicos, edictos y cartas pastorales, procesos episcopales. La primera parte, de carácter introductorio, aborda la problemática de las relaciones entre la religión institucional y la cultura popular. La segunda analiza las funciones de este género de documentación eri el contexto de la época, en una secuencia diacrónica, a fin de observar las

permanencias y también sus cambios a través de los sigios.
\end{abstract}

ABSTRACT

This article is an approach to the analysis of some of the main sources for the study of popular religiosity in Spain during the Ancien Régime. They are often used by historians of mentalités: sermons, catechisms, episcopal synods, pastoral visits, liturgical books, pastoral edicts and letters, episcopal lawsuits. The first part, of an introductory nature, deals with the relations between institutional religion and popular culture. The second analyses the functions of this kind of documents in the context of the period, in a diachronic sequence, in order to observe permanences and changes through the centuries.

El historiador francés Jean Delumeau en dos célebres libros ${ }^{1}$, rompe definitivamente con el esquema tradicional, inmutable hasta entonces en la historiografía europea, de una Edad Media plenamente cristianizada. En uno de los capítulos más interesantes de su libro Le catholicisme entre Luther et Voltaire, que lleva

\footnotetext{
1 J. Delumeau, Naissance et affirmation de la Réforme, París, 1965; Le catholicisme entre Luther et Voltaire, Paris, 1971. Este historiador junto a André Vauchez son los dos historiadores más representativos de la herencia intelectual de la corriente religiosa de inspiración católica que se desarrolla en Francia a partir de 1930 y que tiene en Gabriel Le Bras y Etienne Deruelle a sus dos máximos exponentes.
} 
como título Le mythe du Moyen-Age chrétien, Delumeau se muestra convencido de que en el modelo de cristianismo de la sociedad preindustrial europea del Antiguo Régimen -la Iglesia católica aliada del aparato político del Estado absoluto, en lo que comúnmente se ha dado en llamar alianza trono-altar-la cristianización era mucho más débil de lo que hasta entonces se creía y, consecuentemente, la descristianización posterior de la sociedad no tuvo las dimensiones que tradicionalmente se le otorgaban. Con estos enunciados teóricos, Delumeau transforma radicalmente la interpretación dominante respecto al papel asignado a la Iglesia católica en el marco de la cultura medieval, y el impacto de la Contrarreforma sobre la gran masa de los fieles.

Esta idea motriz fue el germen que generó la producción de sucesivas e interesantes investigaciones en el campo de la historia religiosa de las sociedades europeas. La mayoría de los historiadores dedicados al estudio de esta parcela historiográfica son deudores intelectuales de las hipótesis pioneras de Jean Delumeau, y están de acuerdo en que la Europa de principios del siglo XVI es un conglomerado heterogéneo de diferentes herencias culturales transmitidas a lo largo de los siglos.

La cultura docta europea occidental de los albores de la Edad Moderna es, de hecho, un mosaico de aportaciones sucesivas de diversas culturas que durante todo el período medieval habían sedimentado el panorama cultural de la sociedad continental. La cultura antigua greco-romana, el legado celta y germánico, y la marca de la influencia árabe, impregnaron la vida intelectual de Europa durante toda la Edad Media. De las tres, sólo la cultura latina penetró profundamente en la base del enciclopedismo medieval representada por la filosofia escolástica, verdadera columna vertebral de la mentalidad cristiana. Por su parte, la herencia celta y germánica abrazó especialmente las regiones europeas de origen, limitándose su influjo cultural a las regiones del norte de Europa, no dejando marca profunda en la cultura sabia de Occidente. Respecto a la influencia árabe, su penetración sólo alcanzó a la cultura científica (astrología, alquimia, medicina...) a partir del siglo XII.

Las formas religiosas de estos sustratos culturales impregnaron en diferente grado la religiosidad de los grupos sociales pertenecientes a la cultura popular. La campaña de reforma espiritual iniciada por los frailes mendicantes en el siglo XIII tiene como uno de sus ejes centrales la despaganización del campo europeo de prácticas consideradas contrarias a la moral y a la teología cristiana.

La religión que la autoridad eclesiástica quería reformar era la mayoritariamente practicada por la población campesina de la Europa Moderna, que representaba el 80 u 85 por ciento del total en relación a la residente en las ciudades. Se trataba, fundamentalmente, de la religión de las masas trabajadoras rurales o semirurales masivamente analfabetas, en contraste con la religión oficial, propia de la institución eclesiástica, con su dogma y doctrina plenamente codificado, con el cual los grupos de la elite cultural laica y eclesiástica - predominantemente urbanos- estaban identificados. Una de las finalidades del movimiento reformista ca- 
tólico será depurar de la sociedad cristiana todos las conductas y las creencias consideradas erróneas. En este marco se encuadraban los comportamientos y las prácticas calificadas de supersticiosas y que los reformadores atacaban y desprestigiaban en el curso de su instrucción pastoral.

La religión popular que los reformadores calificaban de meras falacias y supercherías producto de la ignorancia popular no era un ensamblaje de creencias desfasadas procedentes de períodos anteriores. En Europa, bajo la presión evangelizadora de las ordenes mendicantes, tiene lugar entre los siglos XIII-XV una evolución fundamental. El viejo sustrato cultural de tradiciones folklóricas antiguas - largamente deudor del antiguo fondo de la cultura indoeuropea - se transforma substancialmente por las aportaciones de la cultura eclesiástica.

Esta contaminación da como resultado la aparición de un conjunto de creencias distintas según las épocas históricas y con una gran variedad de modalidades locales, diferentes a las que propugna la institución eciesiástica, pero que, sin embargo, poseen una estructura coherente que intenta dar respuesta a un mundo exterior considerado hostil. La Iglesia cristianiza parcialmente un folklore que no desaparecerá completamente hasta la consolidación del modelo económico capitalista y la liquidación de las formas tradicionales de vida del que formaba intimamente parte ${ }^{2}$. La religión cristiana deviene entonces una religiosidad popular. Dos maneras de interpretar el mundo aparecen definidas sobre el escenario cultural de la Europa de la Baja Edad Media: la religión oficial de la institución eclesiástica, y la religión folklórica practicada por la inmensa mayoría del pueblo.

Religión institucional y religión popular se mueven en lógicas distintas. La primera se orienta hacia un conjunto de doctrinas espirituales y prácticas litúrgicas y sacramentales destinadas a liberar a los hombres del pecado mortal y facilitar así los medios para conseguir el camino de la salvación eterna. Las personas están sometidas a un riguroso código de conducta moral, bajo la terrible y amenazadora figura de un Dios que premia y castiga según los merecimientos a los que se hayan hecho merecedores los hombres, y donde el sacerdote es el único intermediario entre la divinidad y los fieles.

Por su parte, la religión popular se articula alrededor de la necesidades vitales de la sociedad. Más que un código de conducta moral, la religión es percibida como un sistema eficaz de procedimientos profilácticos destinados a conjurar los peligros cotidianos de la vida. Surge, de este modo, un heterogéneo sistema de creencias, no idéntico al prescrito por la Iglesia institucional, producto de una larga sedimentación cultural. Estamos en presencia de una religión familiar y espontánea, poco inclinada a las rigideces impuestas por el clero episcopal, donde las instrucciones morales propugnadas por la Iglesia son en muchos casos desoídas y los hombres buscan tener un contacto más directo con Dios, sin nece-

2 J-CL. SCHMiTr, «Religion populaire et culture folklorique», Annales, 5 (1976), pp. 941-953. 
sidad de acudir a la intermediación del clero. La religiosidad popular se manifiesta especialmente bajo formas de espiritualidad fundamentadas sobre prácticas devocionales comunitarias (procesiones, rogativas, peregrinajes...), más que en el estudio y práctica cotidiana de la doctrina cristiana del catecismo y la reflexión religiosa individual. Michel Meslin caracteriza el fenómeno religioso popular en una triple dimensión: antiintelectualista, afectivo y pragmático ${ }^{3}$. En esta misma línea se expresa la historiadora italiana Carla Russo para la cual la lógica interna de la religión popular: "manifiesta una hostilidad a la objetivización sistemática de la creencia religiosa, siendo una explosión de afectividades subjetivas, incorporando lo divino al horizonte mental cotidiano del hombre, humaniza al Dios para sentirlo más próximo, y quiere probar su poder a través de técnicas del cual él es su inventor" ${ }^{4}$.

No obstante, la religión enseñada por la Iglesia oficial y la religión practicada por el pueblo no son en ningún caso dos compartimentos estanco. Jean-Claude Schmitt dice que todo ello forma parte de un proceso de asimilación cultural de profunda cohesión interna donde la forma institucional de la doctrina cristiana y la forma popular del cristianismo no están separadas ni son independientes la una respecto a la otra ${ }^{5}$. El historiador polaco Alexandre Greysator es de la misma opinión, ya que según su parecer las formas y los contenidos de la religión predicada por la Iglesia se engloban dentro del fondo cultural del folklore antiguo europeo de arcaicas creencias ${ }^{6}$. Este investigador comparte la misma opinión de ciertos historiadores de las mentalidades religiosas como André Vauchez, Francis Rapp, Michel Mollet et Raoul Manselli, para quienes la Europa de principios del siglo xVI era un territorio donde la religión cotidiana de la gente común estaba fuertemente penetrada de magismo, pero que, no obstante, se conciliaba con la vida cristiana. Es un cristianismo más percibido como un conjunto de ceremonias externas que garantizaban la seguridad de las personas y los bienes materiales, que no una auténtica práctica de interiorización conceptual de los mandamientos de instrucción doctrinales cristianos.

En el fondo de este debate se encuentra la polémica acerca de una cierta continuidad cultural entre las manifestaciones religiosas antiguas, herencia de las religiones arcaicas paganas, y las expresiones de carácter religioso denunciadas por los reformadores registradas en la documentación eclesiástica elaborada a partir del siglo xVI. A este respecto, Agustín Redondo cree que la religión popular de Castilla de finales del siglo $x \mathrm{~V}$ । denota una clara mentalidad mágica reveladora de una escasa cristianización. Bien al contrario, investigadores como William A. Christian. Jr. y Jean-Claude Schmitt rechazan abiertamente la posibilidad de estratos culturales paganos en las conciencias de las poblaciones rurales preindustriales

M. MESLIN, “Le phènomene religieux populaire", Les religions populaires, París, 1971, pp. 5-15.

4 C. Russo (ed.), Società, chiesa e vita religiosa nell'Ancien Regime, Nápoles, 1976, CLXXV.

5 J-CL. SCHMITT, "Religion populaire...", p. 946.

6 A. Greysator, "Les mentalités religieuses populaires en Pologne et en Bohème médiévales", J. Delumeau (dir.), Histoire vecue du peuple chrétien, Toulouse, 1979, pp. 315-329. 
europeas. Según esta interpretación, todas las expresiones religiosas populares, por muy heterodoxas que resultaran para los coetáneos encargados de su reforma, se inscribían en el complejo de creencias cristianas cotidianas. En este sentido Christian señala lo siguiente:

"Tal vez ese concepto de cristianización, que compara la práctica real, por un lado, con unas normas ideales, por otro, merece ser pensado de nuevo. Muchas de esas "prácticas mágicas", como las llama Redondo, forman parte de un comportamiento considerado aún religioso en prácticamente todos los lugares del globo ( $y$, muy en concreto, en la Francia católica tanto como en España). Semejante criterio atemporal, que opone la cristianización a la persistencia de lo mágico, ¿no representa acaso una distinción impuesta a una cultura localista y basada en la tradición oral por una elite foránea y letrada ${ }^{7}$.

Por su parte, Jean-Claude Schmitt piensa que todo ello forma parte de un proceso de asimilación cultural de profunda cohesión interna donde la forma oficial de la doctrina cristiana y la forma popular del cristianismo no están separados ni son independientes el uno respecto al otro: «Rien n'est survécu dans une culture, tout est vécu ou n'est pas. Une croyance ou un rite n'est pas la combinaison des reliquats et d'innovations heterogènes, mais une experience n'ayant de sens que dans sa cohesion présente ${ }^{8}$. Según esta interpretación, es preciso, pues, evitar caer en la fácil trampa de querer distinguir las creencias y las prácticas que son verdaderamente religiosas de las que son supersticiosas y mágicas dentro de una cultura especifica, actitud a la que tan proclives eran los antropólogos culturales del siglo XIX.

La corriente de opinión contraria a la que acabamos de enunciar la sostienen ciertos historiadores que se inclinan por la continuidad en el tiempo de expresiones religiosas paganas que se prolongarian hasta bien avanzado el siglo XVII. Algunos investigadores defiende la posibilidad de la pervivencia de ritos, creencias y conductas religiosas herederas directas del paganismo que beben en la fuente del arcaico fondo cultural precristiano europeo, y que estarían bien vivos en los primeros siglos de la Edad moderna. En este contexto, J. Michelet, A. Runeberg, M. Summers, E. Rose y J. Rusell sostienen la hipótesis que durante buena parte de la Edad Media y Moderna subsiste un culto organizado de liturgias anticristianas de carácter pagano, revestido de aspectos satánicos, heredado de siglos anteriores, y que conoce su manifestación más visible en el sabbat diabólico. Esta hipótesis ha sido atacada duramente por historiadores como J. Delumeau, H. R. TrevorRoper, R. Mandrou, K. Thomas y N. Cohn, aduciendo para rebatirla que sus partidarios se apoyan simplemente en documentos posteriores de los siglos XVl y XVII, obras elaboradas por demonólogos y en relaciones de procesos inquisitoriales. De otra parte, tampoco se explica como pudo mantenerse en silencio durante cerca de mil años la práctica de un clandestino culto precristiano organizado sin

7 W. A. Christian, Religiosidad local en la España de Felipe II, Madrid, 1991, pp. 13-14.

$8 \mathrm{~J}$-CL. SCHMIT, «Religion populaire...", p, 946. 
que las autoridades religiosas medievales se percatasen, y que súbitamente reapareciera a la luz después. Añaden estos mismos historiadores, que aunque fuese cierto que algunas personas se agrupasen para participar en antiguos ritos mágicos de fertilidad, en ningún caso se las puede calificar de gente pagana, puesto que según sus propias declaraciones escrituradas en los procesos inquisitoriales, se consideraban como cristianos, y no tenían la más mínima intención de atacar al cristianismo. Opinión, ésta, plenamente compartida por C. Ginzburg y G. Henningsen en sus estudios sobre la continuidad en la Europa del siglo XVI de creencias y comportamientos trasmitidos por culturas entonces desaparecidas. Aquí, más que centrarse en los debates entre la continuidad o no de las formas y contenidos del paganismo precristiano dentro de la religión cristiana, conviene examinar de cerca la cuestión fundamental de las relaciones entre la religión oficial y la cultura religiosa popular.

Entre la cultura eclesiástica y la cultura popular se establecen diversos canales de comunicación que actúan a modo de vasos comunicantes, en una dinámica de relaciones e intercambios binarios, donde la cultura del pueblo no es un simple receptor pasivo de los valores vulgarizados transmitidos por la Iglesia, la teoría dominante entre cierto sector de la historiografía medieval, que niega cualquier posibilidad de creación original de producciones culturales propias dentro del marco de la cultura popular europea medieval. Una opinión, que con matices, es compartida en gran medida por el antropólogo norteamericano William A. Christian Jr. para la religiosidad de las comunidades castellanas y catalanas de la Baja Edad Media $^{9}$. Este investigador estadounidense prefiere calificar la religiosidad vivida por los laicos bajo la denominación de "religión local», ante la imposibilidad de definir un concepto tan abstracto como «popular». Si bien Christian le concede cierto grado de autonomía creativa, considera, sin embargo, que su margen de maniobra es ciertamente estrecho. Su grado cognitivo de creación es bajo. Concibe la llamada "religión local» como poseedora de un comportamiento de representación de la realidad circundante ciertamente limitado, caracterizado por una adaptación a sus propias estructuras mentales de los modelos culturales transmitidos por la cultura eclesiástica, que no implican en ningún caso una quiebra del marco ortodoxo oficial. La religión local es presentada como un centro receptor que acoge y estructura según su propia lógica interna los valores externos que le son transmitidos, reordenando un orden de prioridades dentro de una escala de valores previamente existentes.

Por su parte, Jean-Claude Schmitt opina que es más apropiado hablar de procesos multiculturales que no de realidades binarias cuando se aborda la problemática de la cultura europea preindustrial:

"Je refuse, avec Peter Brow, le modèle "à deux niveaux" qui privilegie la seule influence de la culture ecclésiastique sur la culture populaire. Je suggère de réflechir,

${ }^{9}$ W. A. Christian, Religiosidad local... 
à l'inverse, sur la culture médiévale en temps de pôles multiples et de relations complexes, d'une façon que je crois plus proche des réalités concrètes du tissu social; il n'y a pas une culture ecclésiastique, ni une culture paysanne, ni une culture urbaine, mais des thèâtres locaux d'ambitions et de conflits qui mettent en jeu tel ou tel segment de la société, ici les pretentions d'un lignage chevaleresque, là le role de la prédication des religieux mendiants dans le parroises, ailleurs encore la volonté d'affranchissement d'une commune urbaine ${ }^{10}$.

Este historiador francés vinculado a las tendencias de la revista Annales y a los planteamientos metodológicos de Jacques Le Goff, defiende en sus trabajos la premisa fundamental que la sociedad europea de la Edad Media no canaliza una sola forma de racionalidad. Pese a reconocer el peso dominante de la teología de la elite clerical en la elaboración de las representaciones conceptuales de la cultura de la Europa medieval, y su influencia en la construcción de los modelos sociales culturales, ello no imposibilita, según la opinión del investigador galo, que otros modos de pensamiento se yuxtapongan, se enfrenten o se mezclen, aportando los ejemplos de la casuística jurídica, la conciencia caballeresca de la aristocracia laica o los comportamientos religiosos de la cultura popular. Los sistemas de conceptualización de la realidad de estos diferentes modos de percibir la racionalidad no siempre son idénticos, y por consecuencia, necesitan ser tratados de manera particular. Schmitt propugna especialmente evitar la tentación de aislar y parcelar los diferentes niveles sobre los cuales se estructura el marco de relaciones de la sociedad medieval (materiales, sociales y mentaies), que determinan en cada coyuntura histórica los vínculos entre cultura docta y cultura popular. Por el contrario, todo ello se ha de inscribir dentro de una perspectiva holística de la sociedad en que se desarrolla, dentro del conjunto de relaciones e intercambios que se producen entre los diferentes polos de las culturas.

A medida que transcurren los últimos siglos de la Edad Media se va abriendo camino entre los hombres doctos de la Iglesia una nueva sensibilidad religiosa que propugna un cambio radical respecto al orden anterior: ya no es suficiente para ser considerado un buen cristiano el recibir periódicamente los sacramentos, dirigir plegarias a Dios o a los santos, ofrecer limosnas $u$ ofrendas a la Iglesia, etc. Se exige algo más. A partir de entonces se pedirá al cristiano que concilie la practica cotidiana religiosa con el conocimiento intelectual del dogma cristiano revelado por Cristo. Es en este marco cultural donde la Iglesia española tendrá que afrontar su encarnizado combate espiritual a partir del siglo $\mathrm{XV}$, cuando toda una serie de medidas de reforma pastoral son puestas en funcionamiento.

Coincidiendo con la reforma del clero español empezada por los Reyes Católicos bajo los auspicios del cardenal Francisco Jiménez de Cisneros, y continuada luego por Carlos V y posteriormente Felipe II, que tenía como finalidad principal mejorar la categoría moral e intelectual de un clero considerado entonces indigno

10 J-CL. SChMiTt, “Préface», Le corps, les rites, les rêves, le temps. Essais d'anthropologie médiévale, Paris, 2001, p. 18-19. 
para las labores pastorales que se le demandaban; tuvo lugar, simultáneamente, en las últimas décadas del siglo $x v$ y primeras del $x V I$, una amplia ofensiva cuidadosamente planificada de penetración catequética en las ciudades y pueblos de España, como instrumento eficaz de educación cristiana y sumisión de las almas a los preceptos de la Iglesia. Un proceso semejante se iniciará en la mayoría de los países europeos en el transcurso de aquellos años y se prolongará a lo largo de todo el Antiguo Régimen. El Concilio de Trento va a reforzar esta política pastoral reflejada en la intensa campaña de evangelización misionera emprendida por las distintas ordenes del clero regular, cuyo objeto es depurar de la religión vivida por el pueblo toda creencia y práctica ceremonial considerada incompatible con el nuevo proyecto de sociedad surgido de Trento.

Para llevar a cabo este trabajo los clérigos utilizaron intensamente todo un sistema de métodos y procedimientos de adoctrinamiento de masas, cuyo análisis permite al historiador recuperar gran parte de las principales experiencias religiosas cotidianas de las personas comunes. Nuestro análisis se centrará en el estudio de seis tipos de fuentes documentales: sermonarios y catecismos, sinodos diocesanos, visitas pastorales, libros litúrgicos, edictos y cartas pastorales y procesos episcopales.

\section{SERMONARIOS Y CATECISMOS}

Una de las fuentes principales para el estudio de esta vertiente de la fenomenología religiosa la constituyen los sermones, las homilías y las instrucciones doctrinales de los catecismos y manuales de confesores, así como los exempla y relaciones de sucesos - a menudo insertos en las páginas de las fuentes anteriores- conservados en elevado número en forma manuscrita o impresa.

El contenido de esta literatura representa el más importante procedimiento de difusión de la teología pastoral católica durante la Edad Moderna, y uno de los instrumentos más eficaces de influencia sobre las mentalidades populares ${ }^{11}$. Desde la

11 Acerca del panorama historiográfico de esta faceta de la historia social de la religión son importantes los siguientes trabajos: J. Berlioz, M. A. POLo DE BELALIEU, Les exempla médievaux, Carcassonne, 1992; H. E. BODEKER, G. CHAIx. P. VEIT (eds.), Le livre religieux et ses pratiques. Etudes sur I'histoire du livre religieux en Allemagne et en France à l'époque moderne, Gottingen, 1991; J-CL. BREMOND, J. LE GofF, J-CL. SCHMiTt, L'exemplum, Lovaina, 1983; D. de COURCELLES, "Sermons et cantiques en Catalogne avant le Concile de Trente", Melanges de la Casa de Velázquez, XXI, Madrid, 1985, pp. 175-192; P. DEYON, "Sur certaines formes de la propagande religieuse au XVle siècle", Annales, Paris, 1 (1982), pp. 16-26; C. Fernández Rodriguez, D. Rosado Martín, F. Marín Barriguete, "La sociedad española del siglo XVIII a través del sermonario. Aproximación a su estudio", Cuadernos de historia moderna y contemporánea, 4 (1983), pp. 35-57; M. HeRRERo GarciA, "La catequística", Historia general de las literaturas hispánicas, Vol. III, Barcelona, 1953; J. Herrero SALGADO, Aportación a la oratoria sagrada española, Madrid, 1971; A. HuERGA, "Sobre la catequesis en España durante los siglos XVXVI", Analecta Sacra Tarraconénsia, 41 (1969), pp. 175-192; VV.AA, Rhétorique et histoire. L'exemplum et le modèle de comportement dans le discours antique et médiéval, Vol. 92, Roma, 1980; y H. MARTiN, Le métier de prédicateur en France septentrionale à la fin du Moyen-Age, 1350-1520, París, 1982. 
Baja Edad Media la Iglesia consideró este método evangelizador como el procedimiento más contundente que poseía para transmitir su código de valores al pueblo cristiano. Las autoridades religiosas eran plenamente conscientes de esta realidad y de ahí la importancia que los padres del Concilio de Trento otorgaron al trabajo educativo fundamentado en la predicación pastoral.

Pese a los indiscutibles progresos de la imprenta, la comunicación oral era el principal medio empleado en la relación doctrinal de la Iglesia con sus fieles. El sermón del predicador era casi siempre el único vínculo del pueblo con la religión, la cultura y la política. La predicación y las lecciones de catecismo eran impartidas por los misioneros apostólicos en sus visitas ítinerantes, y por el clero secular titular de la parroquia los domingos y días de precepto. En esta política, el Concilio de Trento estableció la predicación obligatoria de los domingos, días de fiesta de guardar y Adviento como sistema para instruir religiosamente al conjunto de la comunidad cristiana $^{12}$. Especialmente, el mensaje eclesiástico debía de penetrar profundamente en las conciencias de una cultura popular frecuentemente situada, en muchas de sus creencias, al margen de los preceptos establecidos por la Iglesia institucional.

A menudo se ha reprochado a este tipo de documentación el carácter excesivamente estereotipado y repetitivo de su contenido textual, su falta de originalidad y su atemporalidad histórica, que haría imposible la menor tentativa de análisis profundo de las mentalidades sociales. Esta es la razón por la cual una gran mayoría de historiadores de la Iglesia han mostrado su reticencia a dirigir su atención hacía estas fuentes para el estudio de la problemática religiosa de las colectividades humanas en la Europa del Antiguo Régimen. No ha sido hasta tiempos relativamente recientes, y en el marco de aplicación de la historia de las mentalidades, que determinados investigadores han descubierto la importancia de estos documentos para intentar reconstruir el marco conceptual sobre el cual se articula la relación entre religión institucional y religión popular, a través de sus diferentes canales de expresión ${ }^{13}$. Sobre este particular, Piero Camporesi ha re-

12 Segun Herrero Salgado la oratoria sagrada española de los siglos $x v-x \mid x$ puede clasificarse de la siguiente manera:

a) Sermones del ciclo litúrgico divididos en dos grupos: ciclo temporal de tiempo ordinario - Adviento y Cuaresma- y ciclo santoral, que incluian además de los sermones en honor de los santos, las pláticas pronunciadas en las festividades de Cristo (en los dias de su nacimiento, pasión y el Santísimo Sacramento), de la Santísima Trinidad, y de la Virgen Maria.

b) Sermones de circunstancias que incluian aspectos sociales y culturales (en ocasión de la coronación del monarca, en acción de gracias por haber librado a una localidad de un brote de peste $c$ haber conseguido el beneficio de la fluvia), y panegíricos (exaltación dedicada a un personaje importante).

c) Sermones de misión cuyo objetivo era enseñar la doctrina cristiana.

d) Oraciones fúnebres dedicadas a las grandes personalidades (Papas, Reyes, Principes...).

e) Sermones políticos propios del siglo xix.

Este autor señala que los sermones más influyentes sobre ia sociedad eran los de Cuaresma, Adviento, de circunstancias y de misión.

13 Una excelente exposición teórica acerca de esta cuestión es la de S. HoLTz, Theologie und alltag. Lehre und leben in den predigen der tubinger theologen, 1550-1750, Tubingen, 1993. 
saltado la importancia de estas fuentes para el análisis de la historia de la cultura religiosa:

"Las paginas de los predicadores y de los tratadistas eclesiásticos constituyen una fuente importante para la reconstrucción no sólo de la psicología popular, sino también de la cultura, las ideologías, los mitos de las clases subalternas, fuentes demasiado injustamente desperdiciadas por los beneméritos investigadores en archivos, que suelen caer en la ilusión científica según la cual una serie de datos más o menos justos, más o menos comprensibles, son más reales (y por ello más fascinantes) que una página impresa, descuidada no precisamente por ignorancia, sino por un desdeñoso e inexplicable rechazo programado de un texto que no sea una fuente escrita cuantificable en cifras y porcentajes" ${ }^{14}$.

Los esquemas específicos de valores y conductas que caracterizaban la vida religiosa, especialmente de las comunidades rurales, se manifiestan en este género de documentos que canalizan y transmiten las normas emanadas por la religión institucional. La instrucción pastoral era impartida habitualmente por religiosos profundamente conocedores de la realidad conceptual de las poblaciones a las que dirigian su predicación doctrinal. Como indica el historiador mencionado unas líneas más arriba, estos clérigos poseían:

"Una densa e indignida elocuencia, nada insólita entre estos hombres de la Iglesia que vivían en estrecho y evangélico contacto con los estamentos más bajos e infortunados; más allá de la tradición literario-eclesial del sermón, la predicación y la homilía, el estilo crispado de Canali deja intuir una socialización de la escritura, sobre la que se refleja un conocimiento vivenciado de las masas, una inflexión sobre lo colectivo, subre la triste épica de la privación, el dolor y el mal»» ${ }^{15}$.

Probablemente las obras más ricas de información para descubrir las relaciones entre teología clerical y las concepciones religiosas populares sean los manuales de confesión. Estos textos eran guías destinadas tanto a los sacerdotes como a los fieles que deseaban prepararse a una buena confesión. Cuando iban destinadas a los confesores contenían consejos y directrices sobre el modo de acoger a los penitentes, cómo comprender sus confesiones, las diversas maneras de interrogar y las penas espirituales a imponer. En los manuales dirigidos a los penitentes se instruía acerca de los procedimientos para conseguir un perfecto examen de conciencia, y llegar así bien dispuesto a los pies del sacerdote. Algunos de estos textos obtuvieron una extraordinaria difusión en España y Europa. Este es el caso del Manual de Martín Azpilcueta Navarro que entre los años 1549 y 1625 conoció 57 ediciones en latín, 19 en castellano, 4 en francés y 3 en portugués.

Dentro de la política religiosa de propaganda pastoral, los clérigos entregados a estos menesteres solían recurrir a otro procedimiento pedagógico destinado a la

14 P. CAmporesi, El pan salvaje, Barcelona, 1986, p. 36.

15 ibidem, pp. 64-65. 
instrucción de la moral cristiana del pueblo, y sobre el que conviene detenerse y prestar atención.

A este respecto, uno de los pilares sobre el que se cimentará la política religiosa de la Contrarreforma en Europa, y al que se le ha concedido nula o escasa atención hasta no hace demasiado tiempo, descansa en la relación existente entre el mensaje eclesiástico propuesto por la Iglesia postridentina y la tradición arcaica del pensamiento popular, vinculadas ambas por la cultura escrita y plasmada a través de la literatura manuscrita o impresa de los exempla y las relaciones de sucesos.

Conceptualmente, las dos son narraciones de carácter edificante de las que se valían los predicadores medievales para ilustrar en sus sermones y clases de doctrina cristiana situaciones cotidianas que podian devenir causa de peligro para los hombres, y a las que nunca era ajena la intervención celestial. Para realizar esta labor pedagógica de aculturación religiosa, la Iglesia medieval ejemplificaba muchos de sus argumentos morales sobre las creencias y cosmovisión que poseia la gente iletrada ${ }^{16}$. Según Robert Darnton, entre los siglos XII y XV son las ordenes mendicantes - fundamentalmente dominicos y franciscanos - las encargadas de recoger todo un corpus de tradición oral popular, sin ningún género de contacto previo con la cultura eclesiástica, para a posteriori elaborar un discurso moralizante que siviera como medio de instrucción religiosa ${ }^{17}$. Georges Duby destaca las aportaciones de la cultura religiosa popular al bagaje doctrinal de la religiosidad oficial durante esta fase de la historia cultural europea:

"A ce que le cristianisme du XIVe siècle a reçu des attitudes religieuses spontanées du peuple à un moment où, solis l'influence des prédicateurs dominicains et franciscains, les dirigents de l'Eglise ont voulu se mettre à la portée des masses. A ce moment-là, ils ont dû emprunter un certain nombre de thèmes et de représentations à la culture populaire et les mêler à un ensemble ideologique qui était demeuré, dans ses formes d'expression, purement aristocratiques" 18 .

Los grandes predicadores populares del siglo xv (San Vicente Ferrer, Jean Gerson, Jean Geiler de Kaysersberg...) hacían largo empleo de este procedimiento en sus sermones. En el siglo xVI, con la eclosión del movimiento erasmista, parece existir un cierto pronunciamiento de rechazo a esta forma de adoctrinamiento por parte de la Reforma protestante y la Contrarreforma católica, pero como señalan Claude Bremond, Jacques Le Goff y Jean-Claude Schmitt, su práctica continuó manteniéndose y aún potenciándose tanto entre los predica-

16 Para un buen conocimiento del tema son esenciales los libros de CI. BREMOND, J. LE GOFF, J-CL. SснмітT, L'exemplum..; y J-CL. SchmiTr, La herejia del santo lebrel. Guinefort, curandero de niños desde el siglo XIII, Barcelona, 1984.

17 R. DARNTON, "La campesina cuenta cuentos: el significado de Mama oca", La gran matanza de gatos $y$ otros episodios en la historia de la cultura francesa, Mexico, 1987, p. 24.

${ }^{18}$ Cit. J. Delumeau, «Religion officielle et religion populaire pendant la Réforme et la Contre-Réforme en France", Concilium, 206 (París, 1986), p. 25. 
dores protestantes como entre los católicos ${ }^{19}$. Dentro de esta dinámica cultural, la Reforma católica y la imprenta refuerzan este sistema ideológico de propaganda que la Iglesia quiere imponer en su política de sujeción de cuerpos y conciencias.

Si en los siglos precedentes el uso de los exempla y de las relaciones de sucesos por los predicadores se limitaba a corregir y encauzar, mediante lo que se consideraba la buena regla cristiana del comportamiento, a la reforma del auditorio al que iba dirigido; tras la Reforma fue puesto al servicio de un objetivo: la pastoral del miedo. Fue el cristianismo del terror a la condenación lo que impregnó casi todo su discurso. A fin de proporcionales mayor veracidad, las escenas eran situadas cronológica y geográficamente próximas al entorno y a la realidad más inmediata del público receptor con la intención de provocar el mayor impacto emocional posible al lector y al oyente ${ }^{20}$.

Roger Chartrier al hablar sobre las lecturas populares durante el Renacimiento remarca el carácter estratégico que para la Iglesia representaba el amplio empleo de este género documental en su política de conversión moral:

"Las historias de los occasionnels (relaciones de sucesos) son exempla esgrimidos por una pastoral heredada de la tradición medieval, que se basa en la amenaza de los castigos terribles y la condenación eterna, y que el impreso de amplia circulación toma a su cargo. Estos textos son entonces instrumentos manipulados para denunciar el protestantismo, cristianizar las costumbres, conquistar o reconquistar las almas. Los occasionnels de los años 1570-1630 se ponen al servicio de una causa político-religiosa, la de la Contrarreforma católica, relatos presentados como "verdaderos" y "nuevos", pero que muy a menudo vuelven a utilizar temas y motivos viejos: los de los exempla, las vidas de santos, o inclusive cuentos. Su fuerza persuasiva depende de la credibilidad que le otorgarán los lectores. Los hechos narrados, singulares e inauditos, deben poder ser considerados verdaderos. Para lograrlo se ponen en marcha varias técnicas probadas: la cita que inserta en el occasionnel arrestos y sentencias extraídos de los registros de la cortes de justicia, las declaraciones de testigos calificados por su rango o por su estado (gentilhombres, curas, clérigos, regulares, notables), la acumulación de detalles circunstanciales (nombres propios, indicaciones de lugares, etc), que son asimismo efectos de la realidad. Sólo rara vez el autor pretende haber visto personalmente lo que describe. Si ese modo de acreditación de la verdad del relato sigue siendo muy minoritario, es sin duda porque los acontecimientos extraordinarios que se relatan se inscriben en otras lógicas que los de la pura constatación; muy a menudo son considerados como signos que avisan, anuncian, castigan ${ }^{21}$.

Los temas de esta literatura religiosa se inscriben en la narrativa apologética terrorífica cristiana de reforma moral. Es frecuente, por ejemplo, encontrar men-

19 C.Bremond, J. Le Goff, J-CL. Schmitt, L'exemplum..., p. 57

20 A. REDONDO, "Las relaciones de sucesos dans l'Espagne du Siècle d'Or: un moyen privilegié de transmission culturelle», Les mediations culturelles, París, 1989, pp. 55-66.

21 R. CHARTRIER, "Del libro a la lectura. Lectores "populares" en el Renacimiento", Les livres des espagnols à l'époque moderne. Bulletin Hispanique, Université de Bordeaux, 1997, pp. 321-322. 
cionado el exemplum de un viajero que perdido en pleno bosque en la oscuridad de la noche pierde la confianza en si mismo y lleno de terror empieza a blasfemar de la Virgen María y de los santos. Al instante se le aparece una figura gigantesca de aspecto monstruoso a caballo y con un ejército de jinetes que lo acompañan de no menos horripilante forma, y que el relato identifica como Lucifer y sus siniestras escuadras diabólicas. Ante la terrible visión nuestro viajero huye despavorido a través de la maleza perseguido por esta fantástica aparición. Sólo después de haberse encomendado a la protección de la Madre de Dios la espectral aparición desaparece. Estamos ante un claro ejemplo de narración edificante con un marcado componente moralizante: solamente la ayuda celestial puede librarnos de las acometidas de los demonios siempre prestos a precipitarnos en el camino de la condenación eterna del infierno si nos desviamos de la buena conducta cristiana.

La interpretación cristiana realiza una verdadera obra de ingeniería literaria. Un mito legendario del arcaico folklore europeo identificado como la figura del gigante Hallequin, que adquiere diversas denominaciones semánticas dependiendo del contexto geográfico, ser fantástico que conduce a un siniestro ejército de almas errantes a él encadenadas por haber muerto en circunstancias anormales (accidente, suicidio, recién nacidos sin haber recibido el sacramento del bautismo...), y que por esta razón no encuentran reposo en ninguna parte, es reinterpretado y asimilado al demonio de la tradición cristiana. Ejemplo claro de cómo la tradición mitológica popular es integrada al discurso de propaganda de reforma moral de costumbres.

Otro caso no menos habitual es encontrarnos con narraciones donde las almas de los difuntos se presentan a los vivos para reclamar el cumplimiento de sus últimas voluntades en forma de responsos y misas post-mortem. Recordatorio para los vivos del estricto cumplimiento de sus obligaciones testamentarias hacia sus familiares fallecidos insertado todo ello en un relato donde se entremezclan componentes de la más estricta ortodoxia postridentina, con otros que remiten a contenidos de la vieja religión pagana, (a menudo relacionado con la forma etérea corporal que adquiere la presencia del fantasma, más cercana a la de un animal que a la humana) cuyos sustratos estaban aún bien presentes en la memoria colectiva del pueb!o. De esta manera se facilitaba los medios para su comprensión entre la gran masa de gente iletrada que escuchaba el exemplum de la voz del sacerdote.

Las fuentes de la mitología popular han sido deliberadamente deformadas por el cristianismo para marginar la sacralidad pagana que evocaban, sin por ello desaparecer ${ }^{22}$. Por este motivo e! mayor problema para el historiador recae en la lectura e interpretación de los textos. El trabajo del investigador, en este caso es doble. Por un lado, debe desbrozar los elementos mitológicos subyacentes en los

22 Ph. Walter, Mythologie chrétienne, París, 2003, p. 15. 
textos antiguos cristianos para descubrir los rasgos y las dimensiones ocultas del pensamiento arcaico de la mitología popular en una secuencia diacrónica de larga duración, donde muchas veces se yuxtaponen diversos estratos de sedimentación cultural correspondientes a distintas fases cronológicas de la historia mitológica del pueblo; y de otro, reinterpretar el conjunto del relato dentro de la óptica cristiana de su tiempo, acerca de cual era el objetivo y la finalidad de la narración.

No todos los exempla y relaciones de sucesos registrados en la literatura religiosa beben de la tradición oral popular. Muchas de las narraciones que han llegado hasta nuestros días son meras recopilaciones de hechos sobrenaturales inventados por los clérigos con una clara función hagiográfica de culto a la Virgen María y a los santos. No se observa en su análisis morfológico ningún elemento que pueda atribuirse a la tradición popular. Un buen número de ellos son relatos estereotipados que reproducen fielmente las imágenes y símbolos de la literatura culta, especialmente de la Biblia y de autores patrísticos y antiguos (por ejemplo, Vida de los Padres de Gregorio el Grande). Otros son simplemente creados por las propias ordenes religiosas con un claro afán propagandístico y difundidos entre los diversos establecimientos religiosos de las respectivas congregaciones, por los intensos desplazamientos de los eclesiásticos que aportaban nuevos milagros y prodigios para acrecentar el prestigio de su comunidad.

La lengua comúnmente utilizada en su redacción era la vernácula del territorio. De esta manera se facilitaba su acceso y comprensión al mayor número posible de público. Así sucedía en Cataluña. En este sentido, recientes investigaciones apuntan que el controvertido retroceso de la lengua catalana en el ámbito literario en beneficio del castellano a partir del siglo $\mathrm{xVI}$, idea que tradicionalmente se ha sostenido para explicar la decadencia literaria del catalán, sólo se produjo en el marco de la gran literatura, no así en los géneros menores, como el aquí tratado, que continuaron manteniendo un enorme desarrollo en el siglo XVIII23.

Desgraciadamente, una considerable cantidad de exempla y de relaciones de sucesos, tanto manuscritos como impresos, anteriores al siglo XVII, sufrieron un proceso de destrucción sistemático a través del tiempo y son ciertamente escasos los conservados. Una gran mayoría eran copiados a mano en pequeñas cuartillas de unas pocas hojas y toscamente encuadernados, que el uso constante hacía inservibles.

Sobre esta problemática, Ricardo García Cárcel pone en aviso a los historiadores de los riesgos que conlleva dejarse arrastrar por criterios estrictamente cuantitativos a la hora de afrontar los recuentos de libros registrados en los inventarios notariales de un período histórico determinado, sin tener previamente en consideración todas las circunstancias posibles:

23 H. Kamen, Cambio cultural..., p. 391. 
"El historiador debe tener en cuenta la información presente y la información ausente en los inventarios. Roger Chartrier dice que si sólo nos fijamos en los inventarios podría dudarse de la existencia de la Biblioteca Azul. La ausencia o escasa presencia en las relaciones de lunarios o literatura panfletaria no implica la inexistencia efectiva en las bibliotecas de este tipo de libros. La gran divulgación es relegada en beneficio de la distinción de los libros de mayor fuste. Lo significativo para un notario no es lo estadisticamente representativo. El excesivo uso de los libros condena determinados libros al riesgo de una desaparición física y su no presencia en los inventarios ${ }^{24}$.

Por su parte Victor Infantes señala que en los inventarios de las bibliotecas faltan los impresos de más amplia y documentada lectura y utilización ${ }^{25}$.

Por estas circunstancias arriba mencionadas resulta difícil intentar reconstruir la vida religiosa de la gente común de las comunidades rurales españolas durante la Edad Media y la mayor parte del periodo moderno. Disponemos, no obstante, para ios siglos XVI-XVIII de diversas fuentes documentales complementarias que nos permiten aproximarnos a la realidad de la religión vivida por la clases populares durante la Edad Moderna. Por su importancia, tanto a nivel cuantitativo, como cualitativo, nos referiremos en primer lugar a los estatutos sinodales.

\section{LOS SINODOS DIOCESANOS}

La definición de sínodo es el de una reunión periódica oficial y obligatoria de los miembros del clero diocesano encargados de la cura de almas alrededor de su obispo, para adoptar las reformas y las correcciones necesarias a la disciplina religiosa de sacerdotes y laicos.

EI IV Concilio de Letrán (1215) estableció universalmente la celebración anual de sinodos para que legislaran los aspectos primordiales de la vida sacramental de las respectivas diócesis. Durante la Edad Media y gran parte de la Edad Moderna, los sínodos devienen instrumentos valiosos para controlar al clero parroquial, muchas veces muy poco instruido para la labor que se le exigía y frecuentemente con una conducta moral que dejaba mucho que desear. Esta será una de las funciones primordiales de estas asambleas diocesanas durante la época medieval: difundii los preceptos de la doctrina cristiana entre los clérigos para de este modo remediar la ignorancia de los fieles, en un tiempo en que los seminarios diocesanos eran inexistentes o estaban escasamente organizados. Los sínodos, aparte su aspecto legislativo, eran centros de aprendizaje para el clero de las parroquias, donde se trataban materias doctrinales de la más variada índole, como la manera de impartir la catequesis, los fundamentos básicos de teología que todo buen sacerdote de-

24 R. GARCía CARCEL, "La posesión del libro en la Cataluña del Antiguo Régimen», Les livres des espagnols..., p. 146.

25 V. INFANTES, “Las ausencias en los inventarios de libros y bibliotecas», Ibidem, p. 289. 
bía saber, la naturaleza de los sacramentos y modo de administrarlos, y demás temas relacionados con la instrucción sacerdotal ${ }^{26}$.

Por regla general, los estatutos sinodales diocesanos elaborados en la Edad Media son más representativos de la vida local que los emanados de las asambleas eclesiásticas provinciales más proclives a reflejar la vida de una época de un modo más general. En este contexto, durante la Edad Media los estatutos sinodales son una adaptación de la ley general sinodal provincial archidiocesana a las costumbres regionales e idiosincrasia de cada obispado, siendo más susceptible de plasmar en su ordenamiento jurídico las mutaciones ligadas a la evolución de las costumbres ${ }^{27}$. En contraste, a partir de la segunda mitad del siglo xIV y a lo largo de la centuria siguiente, los sínodos diocesanos tienden a perder su originalidad propia para devenir en muchas ocasiones simples órganos de difusión de los decretos del concilio provincial.

Este es el principal problema con el que ha de enfrentarse el historiador que aborde el estudio de este género de documentación para los siglos XVI al XVIII. Nadie puede garantizar que las constituciones sinodales vigentes en un obispado estuvieran influenciadas en exceso por las de la diócesis vecina, desvirtuando así su carácter local. Otra trampa para el investigador es caer en la ilusión de que la permanencia o alteración del ordenamiento jurídico eclesiástico en secuencia cronológica sea en realidad fruto de su propia dinámica evolutiva interna, olvidando que ello podía ser producto de un mecanismo mimético por parte de la autoridad diocesana que reproduce los estatutos antiguos, sin reflejar las transformaciones culturales que hubieran podido tener lugar en el marco geográfico de su jurisdicción en un determinado lapso de tiempo.

También puede aparecernos el caso inverso, que la legislación sinodal reflejara profundas modificaciones que estuvieran sujetas a las veleidades del obispo de turno, que proyectaria sus criterios y obsesiones personales represivos, moldeando la ley sinodal a su gusto personal y no reflejando en ningún caso la realidad cultural exterior que se quiere reformar. En otras palabras, no sabemos a ciencia cierta si la repetición de los mismos estatutos sinodales durante un prolongado período de tiempo se debe a la persistencia de malas costumbres que se quieren reformar, pese a las reiteradas amonestaciones episcopales, o simplemente responden a una mera inercia; en su caso contrario, también ignoramos si las variaciones son reales o se corresponden a imposiciones del obispo, con una desconexión total de la realidad cultural y religiosa de la diócesis. La documentación sinodal tampoco nos informa de la relación y de los vínculos de las elites sociales con respecto a las clases populares, ni el

26 Para el análisis de los sínodos como fuente histórica y su utilidad para el estudio de la religión popular ver O. PONTAL, Les status synodaux, Lovaina, 1975; P. BogLIANI, “Pour l'étude de la religion populaire au Moyen-Age: le problème des sources", Foi populaire, foi savante, París, 1976, pp. 93-166; y A. Garcia y García, "Religiosidad popular y derecho canónico", La religiosidad popular en España. Vol. I: La religiosidad popu'ar. Antropologia e historia, pp. 231-243.

27 O. PONTAL, Les statuts..., p. 18. 
grado de participación de las clases dirigentes en las creencias y prácticas de la cultura del pueblo.

A pesar de estos problemas y al hecho de admitir que semejante documentación posea filtros y espejos deformantes, no es razón para desecharla. Como señala Carlo Ginzburg una fuente que no sea "objetiva" no significa que sea inutilizable ${ }^{28}$. Con las debidas precauciones en el manejo del material histórico que nos ocupa pueden salir a la luz aspectos particulares de la vida religiosa de la sociedad del Antiguo Régimen. Basándonos en la utilización de estatutos sinodales cuyo valor documental previamente hayamos verificado, podemos deducir el nivel de la práctica religiosa cotidiana en ámbitos tan trascendentes como la disciplina eclesiástica, la liturgia y el ritual, el derecho (testamentos, restituciones...), las costumbres, la economía, etc.

En España durante los siglos XIII y XIV se celebraron pocos sínodos diocesanos, como lo demuestran las convocatorias de las asambleas episcopales del siglo XIV que aluden a los largos períodos que han transcurrido desde la última celebración. A fines del siglo $x v$, coincidiendo con el auge de la prerreforma iniciada por Enrique Jiménez de Cisneros, empezó una fuerte actividad sinodal y que se prolongará en años posteriores. A partir de mediados del siglo xVII comenzó a decaer su ritmo. La progresiva centralización del gobierno eclesiástico en manos de Roma, con la consecuente pérdida de autonomía de las diócesis, y la cada vez mayor intromisión del poder real en los asuntos de la Iglesia, fueron determinantes en esta decadencia sinodal ${ }^{29}$.

\section{VISITAS PASTORALES}

Una fuente complementaria de los estatutos sinodales e imprescindible para el estudio de la historia de las mentalidades religiosas de la Edad Media y Moderna la constituyen las visitas pastorales. Documento administrativo y secreto que los obispos promocionaron especialmente después de Trento como instrumento de control de las conductas religiosas de los laicos, entre otras muchas cosas ${ }^{30}$.

p. 18.

28 C. Ginzburg, El queso y los gusanos. El cosmos según un molinero del siglo XVI, Barcelona, 1982 ,

${ }^{29}$ Una sintesis excelente sobre la historia sinodal de España es la expuesta por Q. ALDEA, T. MARTIN, J. VIVES, Diccionario de historia eclesiástica de España, Vol. IV, Madrid, 1975, pp. 540-553. Actualmente está en curso de publicación una edición crítica de los sínodos diocesanos medievales de la península ibérica. Anieriormente sólo algunas diócesis como Barcelona o Gerona habian efectuado estudios sobre sus sínodos, Es te el caso del libro de J. SANABRE, Los sínodos diocesanos de Barcelona, Barcelona, 1930. No ocurre lo mismo en el caso de Francia, donde en 1963 apareció publicada la compilación de los sínodos franceses emprendida años atrás por la Société d'Histoire Ecclésiastique: A. ARTONNE, L. GuiZARD, O. PONTAL, Repertoire des statuts synodaux des diocèses de l'ancienne France du XIIle à la fin du XVIIle siècle, Paris, 1963.

30 Sobre el alcance y las limitaciones de las visitas pastorales como fuente histórica ver P. BURKE, «Le domende del vescovo e la religione del popolo", Quaderni Storici, 41 (Ancona, 1979), pp. 540-553. 
En Europa las visitas pastorales se iniciaron de un modo más o menos regular, dependiendo de las diócesis, a partir del siglo XIV. El obispado de Barcelona conoció su primera inspección pastoral en 1303. En el transcurso de la visita eran anotados por el obispo o su representante, generalmente el Vicario General u otra persona de elevado rango eclesiástico, el estado material y espiritual en que se encontraban las parroquias, si bien en forma muy desigual, ya que si en algunos registros las descripciones son muy detalladas, en otras relaciones se citan sumariamente.

Por lo general, las visitas mejor documentadas son las que realizaban personalmente los obispos en las parroquias de su territorio diocesano. Desgraciadamente, esta fuente histórica tiene importantes limitaciones. Las parroquias eran visitadas de un modo bastante fugaz por la autoridad religiosa que sólo se detenía el tiempo preciso para realizar inventario de la situación material en que se hallaba la iglesia parroquial, y preguntar a tres o cuatro personas de probada reputación moral residentes en la población, si conocían a personas entregadas a conductas contrarias a los mandatos de la ley de la Iglesia (amancebamientos, adulterios, supersticiones...), y los nombres de quienes las realizaban.

El obispo y su séquito que lo acompañaba visitaban en una jornada diversas localidades, circunstancia que impedía efectuar una profunda labor de control pastoral de las comunidades rurales. La apretada agenda de trabajo de la máxima jerarquía episcopal lo imposibilitaba. En el transcurso de la visita el prelado frecueniemente decía misa, pronunciaba una exhortación doctrinal a los fieles e impartía el sacramento de la confirmación a los niños. La prisa del obispo por terminar su trabajo a causa de su cargado programa de visitas, y las respuestas de los representantes de la parroquia inspeccionada, reticentes en muchas ocasiones a decir la verdad a las preguntas del prelado por el temor a un posible castigo sobre los vecinos culpables de mantener conductas desaprobadas por la Iglesia, y también, por las posibles represalias y venganzas de los denunciados, imponían la mayoría de las veces respuestas falsas o un silencio cómplice. Sólo en los casos de abierto conflicto entre vecinos salian a la superficie los comportamientos deshonestos ${ }^{31}$.

${ }^{31}$ De todos estos inconvenientes era consciente el obispo Josep Climent en su visita pastoral del año 1772 a las parroquias de la diócesis de Barcelona: "La gran necessitat que hi ha de visitar nostra Bisbat nos obliga a no fer en cada parroquia mes detenció que aquella mes precisa, y que indican indispensable; y la ocurrencia de molts punts que en aquella detenció no es poden evacuar, y de altres que novament se van descubrint, nos obliga a deixar obert lo judici, y procés de cada respectiva iglesia per provindenciar en forma de dita visita lo que tingan per convenient" (ADB, Visitas pastorales, Vol. 84, (1771-1774), Visita de Caldas de Montbuy, Fol. 100 (4-6-1772). En otro párrafo de un documento redactado en la ocasión de una próxima visita pastoral de la diócesis, el mismo prelado señala algunas de las principales dificultades para el desarrollo de su trabajo. "Lo propio por lo común sucede con las visitas episcopáles, que con el Sacramento de la Confirmación, siendo pocos los que tienen de ellas la idea que devieran tener. Algunos las contemplan semejantes a las residencias de los juezes seculares, que, yendo a castigar con rigor, se hacen temibles. Otros las miran con indiferencia, y creyendo, que se dirigen solamente a los clérigos, ni aún piensan en salir a recibir al obispo para tomar su bendición» (ADB, Edicte del llustrissim Senyor Bisbe e Barcelona per la població de la Visita de las iglesias parroquials d'est Bisbat, Vol. Cit., Fol. 23. 
Afortunadamente se han conservado muchos registros de visita pastoral de las diócesis catalanas, cuyo análisis secuencial permite, entre las diversas opciones, reconstruir la geografía de los lugares religiosos (parroquias, santuarios, ermitas) y sus respectivas advocaciones en un territorio determinado; conocer el número y el grado de implantación de las cofradías; saber la cantidad de escuelas primarias que funcionaban en el obispado, y si los maestros eran diligentes en su obligación de impartir la doctrina cristiana a los niños; medir la vitalidad de la economia parroquial y cuáles eran sus recursos de financiación, etc.

En contrapartida, las visitas nos informan poco sobre las costumbres cotidianas del pueblo que la Iglesia desaprobaba (sexo, superstición, juegos...). Existen escasas referencias concretas sobre este particular dentro de la voluminosa información registrada en los libros de visita. Parece ser que en bastantes ocasiones los hombres y las mujeres acusados de estas faltas recibian una simple amonestación verbal por parte del obispo que ni siquiera se molestaba en escriturar el hecho. Procedimiento casi idéntico al empleado por los inquisidores en sus visitas itinerantes.

\section{LOS LIBROS LITURGICOS}

No menos importancia tiene para el estudio de las formas religiosas populares el contenido de los libros litúrgicos. Abordar su análisis significa penetrar en un terreno prácticamente desconocido de la historia española de las mentalidades. Las prácticas religiosas mencionadas en esos libros devienen de hecho un inmenso dossier documental sub-explotado, cuya observación nos aproxima a facetas y a aspectos velados de la vida cotidiana de las personas que otras fuentes históricas silencian.

Los particulares esquemas de valores y conductas que caracterizaban la vida social de los hombres de entonces se manifiestan en este género de documentación. Los contratiempos atmoféricos, el clima de inestabilidad social ante la amenaza de guerras, la inquietud constante ante los flagelos naturales traducida en forma de periódicas pestes devastadoras, hacían bascular la existencia diaria de las personas en un ejercicio de supervivencia cotidiano más bien incierto. La iglesia pone todo su aparato litúrgico al servicio de los hombres como arsenal de recursos destinado a cubrir sus ansias de seguridad. Respuesta a un mundo considerado hostil, el lenguaje ritual expresa la percepción social de antaño $0^{32}$.

32 Para un estudio general de esta temática ver las siguientes obras: J. DeLumEAu, Rassurer et protéger. Le sentiment de sécurité dans loccident d'autrefois, Paris, 1989; P. M. Gy, Les livres liturgiques, Lovaina, 1990; A. AUSSEDAT-MinvILLES, Histoire el contenu des rituels diocésains et romains imprimés en France de 1476 à 1800 . Inventaire descriptif des rituels des provinces de Paris, Reims et Rouen, 2 Vols, Paris, 1987; J. B. Molin. A. Aussedat-Minvilles, Repertoire des rituels et processionnaux imprimés conservés en France, Paris, 1984; P. M. Gr, "Les rites de bénédiction dans le rituel", Bulletin du comité des études, 1959, París, pp. 651-659; J. B. Mouin. "Introduction à l'étude des rituels anciens", Bulletin du comité des études, París, pp. 675-689; y P. BogLIANI, “Pour l'étude de la religion populaire au Moyen-Age. Le problème des sources", Foi populaire, foi savante..., pp. 93-148. 
La fuente básica en que se recoge todo el formulario ceremonial del que se valía la Iglesia para manifestar toda su fuerza protectora se encuentra depositado dentro de los misales y rituales diocesanos, obras litúrgicas que oficializan la vida religiosa de las distintas provincias eclesiásticas, regulando las ceremonias a cumplir por el clero y los fieles en la misa y en otros oficios (procesiones, letanías, sacramentos...), así como los procedimientos a seguir para administrar e impartir las bendiciones y expulsar a los demonios mediante la imprecación de los exorcismos. Muchas parroquias también poseían sus propias prácticas litúrgicas que no contravenian las normas oficiales y eran respetadas por la autoridad episcopal de la diócesis. Los usos y costumbres locales eran registrados en las consuetas parroquiales.

El misal es el libro litúrgico usado por el sacerdote en la celebración de la misa. Es el resultado de la fusión en un solo volumen de diversos libros de la liturgia medieval, básicamente el leccionario y el antifonario, los cuales se combinarán a partir del siglo ix. Antes de 1570 había en España y en todo el mundo cristiano una gran variedad de misales tanto manuscritos como impresos. Cada diócesis introducía en sus consuetudes sus propias ceremonias sin permiso de Roma, prescindiendo totalmente de las que el Sumo Pontífice añadía en su misal de Curia. El Concilio de Trento abordó la cuestión de la reforma del misal en 1563. Sin embargo, la asamblea conciliar no pudo tratar el tema y se remitió el asunto al Papa. Durante el pontificado de Pio $V$ se instituyó la comisión preparatoria para la reforma. La primera edición del misal reformado se hizo en Roma en 1570. El resultado fue la unidad de usos en toda la Iglesia católica. A partir de entonces las diócesis estaban sometidas a los dictados de la Santa Sede sin la posibilidad de introducir nuevos ritos sin su correspondiente autorización. No obstante, esta uniformidad no impedirá que cada obispado rindiese culto a ciertos santos de especial veneración regional, pero siempre bajo el previo permiso de la Curia romana.

El ritual estaba muy lejos de poseer la rigidez y la tradición secular del misal. A excepción de las fórmulas y oraciones esenciales, los rituales de cada diócesis gozaban de una gran autonomía. Antes de Trento no existe ningún ritual oficial común para toda la cristiandad. Un primer intento para unificar los usos litúrgicos se produce en 1523, al publicarse un ritual compuesto por el dominico Alberto Castellano titulado Liber Sacerdotalis, autorizado por el Papa León $X$ y que conoció una veintena de ediciones hasta 1603. Su difusión por el orbe cristiano fue muy restringido, y consecuentemente poco aplicado en las diócesis. En este contexto, el Concilio de Trento apenas si trató la cuestión de la reforma litúrgica, especialmente por la falta de unanimidad de criterio entre los obispos y por la carencia de tiempo para poder abordar debidamente una problemática tan compleja.

El primer ritual auténticamente romano es publicado bajo los auspicios del Papa Gregorio XIII, y será sustituido definitivamente por el ritual de Pablo V en 1614. Aún así, la jerarquía romana no obligaba a los obispos a adoptar forzosamente la liturgia emanada de la Santa Sede, sino que se limitaba a recomendar su 
puesta en vigor. A este respecto, cada diócesis tenía plenas competencias para determinar el número y la calidad de las ceremonias a realizar en su jurisdicción episcopal, dependiendo ello del criterio más abierto o intransigente del obispo de turno que rigiera los destinos espirituales de la diócesis en aquel momento. No era, pues, nada extraño que incluso dentro de una misma provincia eclesiástica cada ritual diocesano pudiera presentar unas características particulares. Frecuentemente se encuentran expresiones como "secundum consuetudinem Vicensis", para referirse a los usos ceremoniales particulares del obispado de Vic -la diócesis más extensa del interior de Cataluña-, o "barcinonensis", para referirse a la de Barcelona. Calificativos que señalaban los diversos procedimientos para administrar los sacramentos, impartir las bendiciones, conjurar los demonios, organizar las procesiones y otras manifestaciones del ceremonial cristiano propias de cada diócesis ${ }^{33}$.

Al hacerse las ediciones impresas de los rituales se introducen muchas devociones y costumbres populares, mientras que otras sospechosas de superstición son suprimidas. Es por ello que un análisis serial a largo plazo de las prácticas y ceremonias eclesiásticas contenidas en los rituales de antes y después de Trento, permite observar el grado de penetración y/o rechazo del espiritu de la Contrarreforma en los distintos obispados, analizando si este proceso es uniforme en todas las diócesis, o si por el contrario, existen muestras tangibles de una acusada divergencia. Factor no menos trascendente es ver la posición que la Iglesia pre y postridentina adopta frente a las demandas populares de protección, y la actitud de los obispos ante determinados comportamientos sociales, así como los conflictos que de ello se derivan como consecuencia de un enfrentamiento entre mentalidades. Este proceso se realizó de una manera harto desigual, al tener ciertos prelados unos criterios más conservadores de la tradición y respetuosos con las aspiraciones del pueblo, que otros, más acordes con la nueva espiritualidad tridentina.

Por lo general, durante el siglo xVI, los obispos españoles mantuvieron una actitud comprensiva hacia las creencias y costumbres de la religión de las clases populares. Muestra de ello es la respuesta a la peticiór que hizo el Concilio de Trento en enero de 1562 para que los prelados remitieran diversos informes sobre distintas materias de las que había de ocuparse el Concilio. De los tres memoriales enviados, en uno de ellos, que respondía al criterio de la mayoría, se mencionaba explícitamente la cuestión de la reforma litúrgica en relación a la religiosidad popular. En el se defendía la postura emanada del Concilio de Basilea (1429), que propugnaba un prudente y racional equilibrio en el acto del ritual católico con el respeto al pluralismo de los ritos y las prácticas locales. Más tarde, con la llegada al trono episcopal de prelados adictos a las ideas reformadores del Concilio tridentino, esta situación variará sustancialmente.

33 A. Franquesa, "Particularismes catalans en els rituals", II Congrès Liturgic de Montserrat, Vol. III, 1967, pp. 91-101. 
Uno de los mejores especialistas europeos sobre la materia, la historiadora francesa Nicole Lemaitre, ha sintetizado admirablemente el núcleo central de la cuestión. Considera las prácticas registradas en los rituales como el resultado, variable según los lugares, de una «negociación entre las prácticas populares y la teología elitista", constituyendo a la vez un indicador del equilibrio entre "las presiones populares en la Iglesia y la voluntad de aculturación clerical ${ }^{34}$. Para este autor, semejante situación habría provocado en el transcurso del tiempo fuertes tensiones entre las dos corrientes, especialmente por las resistencias populares a la supresión de determinados ritos religiosos de carácter protector decididos por el ritual de $\mathrm{Pa}$ blo $V$ y la necesidad en que se encontraron muchos obispos de transigir ante determinadas demandas religiosas de la población. En este sentido, los rituales diocesanos titulados "romanos" mantendrán o suprimirán ciertas ceremonias prescritas en el ritual antes mencionado. Durante el Antiguo Régimen la actitud de la Iglesia estaría estructurada en grandes fases en que alternarian cooperación, tolerancia y represión como respuesta a determinadas coyunturas históricas.

Para el caso catalán la hipótesis propuesta por esta historiadora francesa no respondería del todo a la realidad cultural del territorio. Desde nuestro punto de vista, las prácticas ceremoniales propuestas por la Iglesia católica en la Cataluña Moderna son un instrumento de control de la elite cultural sobre el conjunto de las clases populares que se manifestaría en dos aspectos. De una parte, deviene un corpus doctrinal eclesiástico que refleja los miedos de los grupos sociales dominantes que se quiere transmitir a la cultura popular, fundamentado en la presencia omnipotente del demonio. De otro, la Iglesia absorbe parte de las preocupaciones populares en materia de seguridad, siempre que fueran compatibles con los miedos expresados por las clases dirigentes. Ello provoca un cierto divorcio entre culto litúrgico y piedad popular, cubriendo la Iglesia insuficientemente la protección que esperan de ella las personas ${ }^{35}$. La gente común buscará la solución a sus angustias frecuentemente fuera del marco legal propuesto por las autoridades eclesiásticas. Son precisamente las expresiones litúrgicas situadas fuera del control oficial de la Iglesia, consideradas muchas de ellas como fuertemente supersticiosas y transgresoras a la legalidad del dogma católico, sobre las que los clérigos reformadores dirigirán su atención a fin de erradicarlas.

La reforma tridentina provocó una deflación importante de liturgias dirigidas a proteger los cuerpos y los bienes de las personas, ceremonias que el ritual romano de 1614 ignora totalmente. En un numero considerable de rituales españoles editados antes y después de este año, se observa una espectacular caída en la cifra de oraciones y bendiciones relacionadas con la religión de la tierra y de la salud. Ello propiciado por la labor pastoral de una serie de obispos muy celosos y guardianes de la más férrea ortodoxia católica.

34 N. LEMAiTRE, «Prier pour les fruits de la terre. Pour une étude des bénédictions", Fiestas y liturgias, Madrid, 1988, p. 108.

${ }^{35} \mathrm{M}$. Gelabeato, "L.a liturgia católica: bendiciones y exorcismos en la Cataluña del siglo XVI", E. SERRANO MARTin (ed.), Muerte, religiosidad y cultura popular, siglos XII-XVIII, Zaragoza, 1994, pp. 199-223. 
Sin embargo, hacia finales del siglo xVII y durante la centuria siguiente se introducen prácticas ceremoniales nuevas y resurgen otras que habian sido eliminadas de los rituales impresos en España décadas atrás por poseer un carácter sospechoso de heterodoxia. Habría que preguntarse el por qué de esta nueva situación, no peculiar tan sólo de la península ibérica. ¿Hay que pensar, quizás, en una adición forzada ante las presiones populares, insatisfechas ante los drásticos recortes de años anteriores? ¿Hasta qué grado la ofensiva del regalismo borbónico en el siglo XVIII, reforzando el papel del Estado sobre la Iglesia, se correlaciona con este auge de liturgias protectoras? Esta última hipótesis es la formulada por Annik Aussedat-Minville, que ve una asociación entre los ritos reincorporados a los libros sacramentales franceses del siglo XVIII con una ofensiva neogalicana estimulada por la política regalista de los monarcas borbones.

Estas fuentes padecieron un proceso de destrucción sistemático en el transcurso de los siglos. Los rituales más antiguos hallados en Cataluña son del siglo xv. De éstos, los manuscritos son excepcionales - sólo hemos podido localizar un ejemplar de la diócesis de Barcelona datado en 1495-y de incunables no se ha podido localizar ninguno, si nos restringimos al marco geográfico catalán. Los rituales son quizás los libros religiosos más difíciles de encontrar, pues el uso constante los hace inservibles. Su progresivo deterioro es la principal razón que aducen los obispos para mandar imprimir nuevas ediciones, que en su mayor parte difieren sustancialmente con respecto al contenido de los libros ceremoniales anteriores vigentes en las diferentes diócesis. Son precisamente estas transformaciones cronológicas del ritual lo que confiere interés a los ojos del historiador.

Es habitual leer en los libros de visita pastoral disposiciones referentes al deplorable estado de los textos litúrgicos en muchas parroquias. Por este motivo son muy pocos los ejemplares que nos han llegado del siglo $x V I$, $y$ de los siglos XVII y XVIII en un elevado porcentaje aparecen degradados por su uso. Un botón de muestra lo tenemos en la diócesis de Urgel. Del primer ritual impreso, aparecido en 1515 , no se conserva ningún ejemplar ni tampoco se tiene indicio alguno de cual podía ser su contenido ${ }^{36}$.

En las parroquias a la liturgia oficial de la diócesis se la añadían las ceremonias religiosas locales mencionadas en unos cuadernos que en Cataluña recibian la denominación de consuetas. Las consuetas parroquiales tienen una doble función: jurídico-canónica y económica. Son un inventario descriptivo de las costumbres litúrgicas peculiares de la localidad y un libro donde se registraba la gestión patrimonial de la iglesia y los recursos materiales de los que disponia cada parroquia. La consueta servia para que los nuevos rectores conocieran de primera mano las obligaciones concernientes a las prácticas y las costumbres de la vida religiosa local (modo y orden de hacer las procesiones, fiestas de guardar, oficios divinos...), y la fuente principal para conocer las rentas disponibles y los recursos

${ }^{36}$ A. MOLINE, “La visita canónica de l'oficialitat de l'any 1515», Urgellia, VII, pp. 441-463. 
económicos que generaban (celebración de aniversarios, administración de la iglesia, fundación de cofradias...). La consueta parroquial era en realidad un libro mixto, donde aparte de estar inventariados todos los ritos y ceremonias de la iglesia de la localidad, se escrituraba información referente a la actividad económica de la parroquia. Así, junto a la vertiente estrictamente religiosa del texto aparece una parte con una extensa lista de nombres de casas rurales, con las respectivas cantidades de dinero a pagar por cada una de ellas en concepto de impuestos. Por este motivo, las consuetas parroquiales son una preciosa fuente histórica para conocer la demografía, la distinta categoría económica de las casas que componían el núcleo rural, la delimitación territorial de las parroquias, etc. El estudio de su contenido tiene un doble interés para la investigación de la historia de la liturgia y la historia económica. A partir de la segunda mitad del siglo XVII, y especialmente, en el siglo XVIII, las consuetas pierden su carácter económico, centrándose únicamente en los usos y las prácticas de culto ${ }^{37}$.

\section{EDICTOS Y CARTAS PASTORALES}

La administración eclesiástica generaba una prolífica documentación de la que una parte es aprovechable para nuestro interés. Los edictos y las cartas pastorales que se colgaban a la entrada de los templos o se leían durante el oficio de la misa tenían como finalidad hacer llegar a los fieles las decisiones de Roma o del obispo de la diócesis referentes a las más variadas cuestiones (prohibiciones de fiestas, concesiones de bulas pontifícias, etc.). A menudo también incluían disposiciones acerca de la represión de las actividades contrarias a la fe de la doctrina cristiana. Estas fuentes proporcionan valiosa información sobre la vida religiosa cotidiana de la diócesis, informándonos de bastantes facetas de la religiosidad de la gente común, especialmente interesantes durante el siglo xvI, en los prolongados periodos en los que las sedes episcopales estuvieron vacantes de obispo titular.

Sobre este último aspecto es conveniente añadir ciertos comentarios. La historiografía tradicional siempre ha tenido tendencia a sobredimensionar el papel de los obispos en el trabajo pastoral de las diócesis. Normalmente se ha asociado el absentismo de los prelados, su incompetencia, su desinterés en ocuparse de los asuntos espirituales de sus obispados, o su mala conducta, como factores determinantes en la degradación moral del pueblo por falta de una cabeza visible que llevase las riendas firmes de su sede diocesana, y emprendiera una labor de apostolado firme y continua entre los fieles de su territorio diocesano. Sin embargo, la moderna historiografía religiosa está revisando esta clásica interpretación, reclamando la atención de los historiadores sobre las jerarquias clericales intermedias episcopales presentes en la mayoría de las diócesis occidentales (arciprestes, vicarios generales, deanes...), clero que formaba parte del gobierno de la diócesis

37 A. Pladevall y J. M. Pons Guri, "Particularismes catalans en els costumaris dels segles XIIIXVIII", /l Corlgrès Liturgic..., pp. 103-159. 
y activos miembros colaboradores del obispo. Gracias a estos cargos eclesiásticos muchos obispados estaban espiritualmente bien gobernados, asegurando la disciplina eclesiástica y la correcta vida espiritual de la gente ${ }^{38}$.

\section{PROCESOS EPISCOPALES}

Los procesos episcopales elaborados a lo largo de todo el Antiguo Régimen por las distintas curias diocesanas españolas son una fuente de información inmensa a la que hay que prestar mucha atención. No obstante, y pese a los miles de legajos escriturados en el transcurso de los siglos, las informaciones proporcionadas son muy desiguales de unos territorios eclesiásticos a otros. Realmente ignoramos la razón profunda por la cual ciertos tribunales de curia prestaban más atención a unos asuntos en detrimento de otros. Probablemente haya que buscar el motivo en una antigua tradición jurídica que la costumbre no escrita había convertido en ley. Así, mientras que las diócesis aragonesas los procuradores fiscales de las curias diocesanas respectivas se afanaban en incoar procesos contra supuestas brujas culpables de causar multitud de desgracias; en sus homónimas catalanas esta cuestión está prácticamente ausente de los anales jurídicos, y en cambio se presta mucha atención a las conductas y desordenes morales del clero regular y secular, especialmente en lo concerniente a la vida sexual de los sacerdotes y al concubinato clerical ${ }^{39}$. Otros temas de interés que surgen en este tipo de fuentes y que ayudan a reconstruir la sensibilidad religiosa del pueblo son los reiterados procesos a laicos por falta de cumplimiento en guardar y observar los días festivos, con la no asistencia a misa y el no abstenerse de trabajar; las abundantes demandas de separación matrimonial interpuestas por los cónyuges; los conflictos cotidianos entre el cura párroco de la localidad y sus feligreses; la represión judicial de determinados abusos que se atribuyen a las cofradias devocionales en forma de excesivos dispendios económicos en la organización de los actos de culto de la liturgia anual y sobre todo durante la celebración de las fiestas patronales de la localidad, etc. Todo un heterogéneo abanico de comportamientos cotidianos que la Iglesia desaprobaba están reflejados en los procesos judiciales diocesanos. Los tribunales episcopales entendían en delitos que otras instancias judiciales también examinaban, especialmente la Inquisición.

Para terminar señalaremos que el historiador debe preferentemente evitar trabajar con una sola fuente para asi descartar el riesgo de caer en una excesiva focalización documental que implique el estar sometido a las limitaciones de carácter metodológico determinadas por la elaboración de la propia estructura del

${ }^{38}$ En este sentido son muy interesantes las comunicaciones contenidas en VV.AA., Vescovi e diocesi in Italia dei XIV alla meta de XVI secolo (Atti VII convegno della chiesa in Italia), (Brescia, 21-25 septiembre de 1987), 2 Vols, Roma, 1990.

39 J. Marti Bonet, L. Niqui Puigvert, F. Miquel Mascort y J. Codina Vila, Processos de l'arxiu Diocesà de Barcelona, Vol. I, Barcelona, 1984. 
documento, y de las que ya se ha hecho amplia mención en las páginas precedentes al tratar de las características de cada una de las fuentes. Por el contrario, es altamente recomendable apoyarse sobre la fuente cruzada para verificar o rechazar hipótesis de trabajo en un período de tiempo largo, y poder así establecer de un modo más sólido los diversos niveles de interrelación social y cultural producidos en el marco geográfico concreto de aplicación. 